\title{
Chlorophyll-associated genes and SSR markers linked to genetic variations in heat tolerance of perennial ryegrass
}

\author{
Jing Zhang ${ }^{1}$, Hui Li ${ }^{1}$, Yiwei Jiang ${ }^{2}$, Huibin $\mathrm{Li}^{3}$, Zhipeng Zhang ${ }^{4}$, Bin $\mathrm{Xu}^{5}$, and Bingru \\ Huang 6 \\ ${ }^{1}$ Nanjing Agricultural University \\ ${ }^{2}$ Purdue University \\ ${ }^{3}$ Hebei Agricultural University \\ ${ }^{4}$ Shanghai Biotechnology Corporation \\ ${ }^{5}$ Nanjing Agricultural Univerisyt \\ ${ }^{6}$ Rutgers University
}

May 6, 2020

\begin{abstract}
Identification of genetic diversity in heat tolerance and associated markers is of great importance for improving heat tolerance in cool-season grass species. In this study, 98 accessions of perennial ryegrass (Lolium perenne L.) were subjected to heat stress $(35 / 30$, day/night) or optimal growth temperature $(25 / 20)$ for $24 \mathrm{~d}$ in growth chambers. Overall heat tolerance of those accessions was ranked by principal component analysis (PCA) based on eight growth and physiological traits. Among these traits, chlorophyll (Chl) content had the highest correlation coefficient (0.864) with the PCA ranking of heat tolerance, indicating it was the most closely linked parameter to heat tolerance. And expressions of four Chl catabolic genes (CCGs) were negatively correlated with PCA ranking of heat. Furthermore, simple sequence repeat (SSR) markers were identified that significantly associated with Chl content and other heat tolerance-related traits. Together, the result highlighted the importance of Chl catabolism in heat tolerance of cool-season grasses. Chl content, heat-associated CCG genes and their associated SSR markers could be used as reliable trait or molecular markers in the breeding program of perennial ryegrass toward better heat tolerance.
\end{abstract}

Abbreviations: Chl, chlorophyll; TQ, turf quality; Fv/Fm, photochemical efficiency; RWC, leaf relative water content; Pn, photosynthetic rate; WUE, water use efficiency; RA, root activity; LW, leaf width; PH, maximum plant height; PCA, principal component analysis; HSI, heat stress index; SSR, simple sequence repeat; CCGs, Chl catabolic genes.

\section{INTRODUCTION}

Improving heat tolerance is among major efforts of breeding improvement in cool-season grass species (Xu et al., 2018). The available germplasm collections with large genetic variability and a wide range of heattolerance levels are important breeding materials for grass breeding program (Jespersen et al., 2017; Krans et al., 2000; Minner et al., 1983). While lack of genetic variability and limited knowledge of physiological and molecular factors underlying heat stress tolerance restrict the efficiency on identification of heat-tolerant cultivars.

Genetic diversity among germplasms with varied levels of stress tolerance can be evaluated using phenotypic traits and molecular markers (Cao et al., 2015; Li et al., 2017; Varshney et al., 2010). Phenotypic analysis 
focuses on growth, morphological, and physiological parameters among germplasm and provides information regarding genetic diversity, homogeneity, and stability (Li et al., 2017; Ober et al., 2005). Since abiotic stress adversely affect a multitude of morphological and physiological processes, a number of distinct morphological and physiological characteristics have been used as marker traits to evaluate genetic variations in plant stress tolerance, such as root activity (RA), photochemical efficiency $(\mathrm{Fv} / \mathrm{Fm})$, photosynthetic rate $(\mathrm{Pn})$, water use efficiency (WUE), chlorophyll (Chl) content, and leaf relative water content (RWC) (Larkindale et al., 2005; Li et al., 2017; Shah et al., 2011; Zhang et al., 2017). The selection of germplasm based on physiological traits is an efficient approach in breeding for improved stress tolerance in various crop species (Paolo et al., 1998; Rana et al., 2002). In the case of cool-season grass breeding for heat tolerance, it is pivotal to firstly identify phenotypic and/or physiological traits closely correlated with heat tolerance, which traits can be used as markers for the rational development of improved germplasm (Jespersen et al., 2017; Mondal et al., 2015).

Leaf senescence characterized by loss of chlorophyll is one hallmark of heat stress damages in cool-season grass species. Our previous studies found that leaf senescence induced by heat stress was mainly due to heat accelerated chlorophyll ( $\mathrm{Chl}$ ) catabolism rather than attenuated Chl biosynthesis in one cool-season grass, creeping bentgrass (Agrostis stolonifera) (Jespersen et al., 2016) and reducing Chl catabolic rate by suppressing a Chl catabolic gene $(P P H)$ in perennial ryegrass (Lolium perenne L.) delayed heat-induced leaf senescence (Zhang et al., 2019). Selecting for stay-green traits by controlling chlorophyll loss or leaf senescence is of great significance for developing heat-tolerant cool-season grass cultivars using leaf senescence-related parameters for heat tolerance assessment.

Molecular markers linked to phenotypic and physiological traits have been developed to understand the genetic diversity and to predict desirable traits of a given germplasm or breeding materials (Li et al., 2017). To date, molecular makers associated with several important agronomic traits of perennial ryegrass have been developed, including crown rust resistance (Dumsday et al., 2003), drought tolerance (Yu et al., 2013), winter survival and spring re-growth (Yu et al., 2015), submergence (Yu et al., 2011), and salinity tolerance (Tang et al., 2013). For examples, Yu et al. (2011) evaluated the submergence tolerance of 99 diverse perennial ryegrass accessions using 109 simple sequence repeat (SSR) markers, and identified 15 pairs of SSR markers associated with alterations of several morphological and physiological traits (e.g. leaf color, Fv/Fm, maximum plant height, and relative growth rate). Tang et al. (2013) analyzed the genetic diversity of 56 perennial ryegrass accessions of different origins using 66 SSR makers, and found that population structure influenced phenotypic traits, and allelic variation in $L p N H X 1$ might explain the variation of salinity tolerance of perennial ryegrass.

Perennial ryegrass (Lolium perenne L.), native to Europe, Asia, and Northern Africa, is the most widely cultivated perennial cool-season grass in the temperate regions worldwide for its turf and forage purposes (Altpeter et al., 2000; Chastain et al., 2015), but it is one of the most heat sensitive grass species. Despite of the diversity of perennial ryegrass to various other stresses and diseases, as discussed above, neither the diversity of heat tolerance among perennial ryegrass germplasm collections was quantitatively measured, nor the molecular markers associated with heat tolerance been developed for this species. The objectives of this study were to determine genetic variations in heat tolerance associated with phenotypic and physiological traits and to identify molecular markers associated with heat tolerance in a diverse collection of perennial ryegrass.

\section{MATERIALS AND METHODS}

\subsection{Plant materials and growth conditions}

A collection of 98 perennial ryegrass accessions was obtained from United States Department of Agriculture's National Plant Germplasm System (USDA-GRIN), including 37 wild, 33 cultivated, and 28 with uncertain pedigree accessions (Table 1). A single seed of each germplasm was sown in plastic pots $(13 \mathrm{~cm}$ diameter and $13 \mathrm{~cm}$ height) filled with fritted clay and maintained in a greenhouse at Nanjing Agricultural University, Jiang Su, China. Each accession was propagated using tillers to generate stock plants. In this experiment, 
tillers from stock plants of each accession were transplanted into eight pots (with each pot has 10 tillers) and maintained in a growth chamber controlled at 25/20 (day/night temperature), $70 \%$ relative humidity, a photoperiod of $16 \mathrm{~h}$, and photosynthetic active radiation of $750 \mu \mathrm{mol} \mathrm{m}^{-2} \mathrm{~s}^{-1}$ for $60 \mathrm{~d}$. Plants were maintained at a height of $12 \mathrm{~cm}$ by weekly mowing and fertilized weekly with half-strength Hoagland's nutrient solution (Hoagland \& Arnon, 1950).

\subsection{Temperature treatments}

Plants in four pots (four replicates) for each accession were exposed to normal growth temperature of 25/20 (day/night) or heat stress at 35/30 (day/night) in growth chambers. Each temperature treatment was repeated in two growth chambers. Plants were subjected to those temperature conditions for $24 \mathrm{~d}$. The plants received regular water and fertilization during the treatment period.

\subsection{Phenotypic and physiological measurements}

At $24 \mathrm{~d}$ of heat stress treatment, growth and physiological parameters, including leaf width (LW), maximum plant height $(\mathrm{PH})$, turf quality $(\mathrm{TQ})$, photochemical efficiency $(\mathrm{Fv} / \mathrm{Fm})$, chlorophyll $(\mathrm{Chl})$ content, leaf relative water content (RWC), photosynthetic rate (Pn), water use efficiency (WUE), and root activity (RA) were measured. For LW analysis, 10 mature leaves of each accession were measured using a digital caliper. $\mathrm{PH}$ was measured manually as the length from the base to the top of each plant. TQ was visually rated using a 1-9 scale based on plant color, shoot density and uniformity to assess the overall plant health and vigor ( 1 represents brown and dead plant, and 9 represents the best plant in all these quality components) (Turgeon, 1991). Fv/Fm was determined using a fluorescence meter (Dynamax, Houston, TX, USA), described previously by Oxborough and Baker (1997). Chl content was measured according to the method by Arnon (1949). In brief, about $0.1 \mathrm{~g}$ of leaves were soaked in $10 \mathrm{ml}$ dimethyl sulfoxide and maintained in the dark for $72 \mathrm{~h}$, and then the absorbance of extracts at $663 \mathrm{~nm}$ and $645 \mathrm{~nm}$ were measured using a spectrophotometer (Spectronic in Instruments, Rochester, NY, USA). For RWC quantification, about $0.1 \mathrm{~g}$ fresh leaves were detached and immediately weighed as the fresh weight $(\mathrm{FW})$, then soaked in distilled water and maintained at $4{ }^{\circ} \mathrm{C}$ in the dark for $24 \mathrm{~h}$ and weighted as turgid weight (TW). Leaf samples were then placed in an oven at $80^{\circ} \mathrm{C}$ for $72 \mathrm{~h}$ prior to being weighted for dry weight (DW). The RWC was calculated as formula: (FW-DW)/(TW-DW) $\times 100 \%$ (Flexas et al., 2006). Pn and WUE were measured according to the method described by Burgess and Huang (2014) using a portable photosynthesis system (Li-COR6400, LICOR Inc., Lincoln, NE, USA). RA was measured using 2,3,5-triphenyl tetrazolium chloride (TTC) reduction method (Comas et al., 2000). The TTC reduction assay was performed following the method of Steponkus and Lanphear (1967) with minor modifications. In brief, approximately $0.5 \mathrm{~g}$ root tips $(0-50 \mathrm{~mm})$ were excised and washed three times with distilled water and transferred to $10 \mathrm{ml}$ TTC solution $(0.4 \%$ TTC in 0.1 $\mathrm{M}$ sodium phosphate buffer, $\mathrm{pH}$ 7.0). After $3 \mathrm{~h}$ incubation at $37^{\circ} \mathrm{C}$, TTC solution was removed and root segments were washed with distilled water. The roots were cut into $1 \mathrm{~cm}$ segments and incubated overnight at room temperature in $10 \mathrm{ml}$ of $95 \%$ ethanol. The reduction of TTC was expressed as the absorbance of the extraction solution at $485 \mathrm{~nm}$.

\subsection{Ranking of overall heat tolerance}

Heat stress index (HSI) was used to evaluate the overall heat tolerance for 98 accessions integrating multiple growth and physiological traits according to the following formula (Bouslama and Shapaugh, 1984), which was expressed as percentage of control, HSI = (value of parameter under heat stress condition) / (value of parameter under control condition) $\times 100$. Principal component analysis $(\mathrm{PCA})$ was used to rank heat tolerance of 98 accession, following the method used in ranking of drought and salinity tolerance for different grass genotypes as described in Liuet al. (2015) and Tang et al. (2013). PCA ranking value for each accession was calculated using the formula: $\mathrm{PCA}$ rank value $=\sum_{j=1}^{n}[\mathrm{PCj} \times$ contribution of $\mathrm{PCj}(\%)] j=1,2,3, \ldots, n$.(Zhu et al., 2014). In this formula, 'PCj' represents the value of principal component $j$ and 'contribution of $\mathrm{PCj}(\%)$ ' represents the variance in response to stress treatment that principal component $j$ could explain. When the total contribution of first several PCs was higher than $85 \%$, these PCs were selected for PCA rank calculation (Huang et al., 2017). Relative heat tolerance of 98 perennial ryegrass accessions was subsequently ranked 
according to their PCA ranking values.

\subsection{Genetic diversity and association analysis}

A total of 66 pairs of publicly available SSR primers of nuclear DNA distributed on seven chromosomes (Supplementary materials 1) were used to genotype the 98 perennial ryegrass accessions (Tang et al., 2013). PCR reaction was performed in a $10 \mu \mathrm{l}$ reaction volume with $60 \mathrm{ng}$ DNA, 1.0 unit of Taq DNA Polymerase, $1 \times$ PCR buffer, $0.2 \mathrm{mM}$ dNTP mix, $2.5 \mathrm{mM} \mathrm{MgCl}_{2}, 0.05 \mu \mathrm{M}$ forward tailed primer, $0.05 \mu \mathrm{M}$ fluorescent labeled M13 primer, and $0.1 \mu \mathrm{M}$ reverse primer. All PCR reactions were carried out in a Bio-Rad thermocycler (BioRad Inc., Hercules, CA, USA) using a touch-down program described by Yu et al. (2013). PCR products were separated in an ABI 3730 DNA Sequencer (Applied Biosystem, Inc., Foster City, CA, USA). Alleles were identified by GeneMarker 1.6 software (SoftGenetics, LLC, State College, PA, USA). The allelic bands with at least $2 \mathrm{bp}$ differences were considered as polymorphic among accessions. All confirmed polymorphic alleles were used for cluster analysis.

Nei's genetic distance among accessions was estimated by the "Phylogeny" function of PowerMarker software version 3.25 based on the SSR marker data (Nei, 1973). The Nei's genetic distance was then used for cluster analysis and generation of Neighbour Joining (N-J) dendrogram by FigTree version 1.4.2 (http://tree.bio.ed.ac.uk/software/figtree/) (Zhang et al., 2019). Association analysis of SSR markers with heat tolerance traits was conducted using TASSEL 5.0 software along with the general liner model (GLM) procedure (Bradbury et al., 2007). P [?] 0.01 was used to identify significant associations.

\subsection{Gene expression analysis}

The Qiagen RNA Extraction Kit (Qiagen, Valencia, CA, USA) was used to extract total RNA form perennial ryegrass leaves following the manufacturer's instructions. The first-strand cDNA was synthesized using the High Capacity cDNA Reverse Transcription Kit (Applied Biosystems, Grand Island, NY, USA). The qRTPCR reaction was performed using the Roche LightCycler (R) 480 II Real-Time PCR System (Roche Molecular Systems, Inc., Branchburg, NJ, USA). All PCR reactions were performed in a $20 \mu$ l reaction volume with four biological replicates. Primers used for qRT-PCR analysis were listed in supplemental table 1 and LpeIHF 4Awas used as a reference gene (Huang et al., 2014).

\subsection{Data analysis}

Data from all samples were subjected to analysis of variance (ANOVA) using SAS 9.3 software (SAS Institute Inc., Cary, NC, USA) as shown in Table 2. Treatment means were separated using Fisher's protected LSD test at a 0.05 probability level as shown in Table 5 and Figure 5. Pearson correlation analysis between physiological parameters was performed using the Bivariate Correlations program in software SPSS for Windows (Version 12, SPSS Inc., Chicago, IL) as shown in Table 4. Heatmap (Figure 1) and principal component analysis (PCA) (Figure 2) of the morphological and physiological parameters were performed using R statistical software (R3.5.2 by R Development Core Team). Correlation between CCGs' expression levels and PCA ranking values was analyzed using linear regression analysis program in Microsoft Office Excel 2013 software (Microsoft Corporation) (Figure 5 \& 6).

\section{RESULTS}

\subsection{Evaluation of heat tolerance in 98 accessions of perennial ryegrass}

A total of six physiological traits (WUE, Pn, RA, Chl content, RWC, and Fv/Fm) and three phenotypic traits (TQ, LW, and $\mathrm{PH}$ ) were used to evaluate heat tolerance of 98 perennial ryegrass accessions. Effects of heat stress treatment, genotype, and interaction of these two factors were all significant $(p[?] 0.05)$ for WUE, Pn, RA, Chl, RWC, Fv/Fm, and TQ. Only genotypic variations were significant for LW and PH (Table 2).

The data for physiological and phenotypic traits of 98 accessions exposed to heat stress or optimum temperature (control) conditions were used to plot a heatmap (Figure 1), in which the hierarchical cluster was clearly grouped into two distinct sub-clusters: accessions under the control condition (sub-cluster ' $a$ ') and 
those under the heat stress (sub-cluster 'b' as shown in Figure 1). Accordingly, nine traits used to evaluate heat tolerance were grouped into three sub-clusters: sub-cluster I included WUE, Pn, and RA, where their values were lower under heat stress than those under control condition; sub-cluster II included Chl content, TQ, RWC, and Fv/Fm, and their values were also lower under heat stress; sub-cluster III, consisting of the two morphological traits, $\mathrm{PH}$ and $\mathrm{LW}$, were not responsive to temperature effects (Figure 1). Therefore, seven traits, WUE, Pn, RA, Chl content, RWC, and Fv/Fm, and TQ were used to evaluate heat tolerance in the following analyses.

\subsection{Ranking of overall heat tolerance for 98 accessions of perennial ryegrass}

The PCA analysis of variations in heat tolerance of 98 accessions based on HSI identified a total of seven principal components (PC 1-7). The sum of the first PCs (PC1 to PC3) explained $86.3 \%$ of the total variance, among which the $1^{\text {st }}, 2^{\text {nd }}$ and $3^{\text {rd }}$ PCs were the major ones explaining $54.3 \%, 23.3 \%$ and $8.7 \%$ of the variance among 98 ryegrass accessions, respectively (Supplementary Table 2). Based on the PCA results, the following formulas were developed (details of the formula were shown in supplementary Table 2 and supplementary Table 3): $\mathrm{PC} 1$ value $=0.915 \times \mathrm{TQ}+0.791 \times \mathrm{Fv} / \mathrm{Fm}+0.858 \times \mathrm{Chl}$ content $+0.369 \times \mathrm{Pn}+0.243 \times \mathrm{WUE}$ $+0.887 \times \mathrm{RWC}+0.789 \times \mathrm{RA} ;$ and $\mathrm{PC} 2$ value $=(-0.186) \times \mathrm{TQ}+(-0.298) \times \mathrm{xv} / \mathrm{Fm}+0.003 \times \mathrm{Chl}$ content + $0.813 \times \mathrm{PPn}+0.900 \mathrm{xWUE}+(-0.172) \mathrm{xRWC}+0.049 \mathrm{xRA}$; and $(3) \mathrm{PC} 3$ value $=0.096 \mathrm{xTQ}+0.366 \mathrm{xFv} / \mathrm{Fm}+$ $(-0.255) \mathrm{xChl}$ content $+0.312 \mathrm{xPn}+(-0.079) \mathrm{xWUE}+0.173 \mathrm{xRWC}+(-0.517) \mathrm{xRA}$, and PCA ranking value $=(54.34 \% \mathrm{xPC} 1)+(23.25 \% \mathrm{xPC} 2)+(8.69 \% \mathrm{xPC} 3)$.

According to PCA results, we clustered 98 ryegrass accessions into two groups:Group-i consisted of 49 accessions with PCA rank value at the top half of all accessions, while the rest 49 accessions clustered to group-ii (Figure 2). Heat tolerance of 98 accessions were then ranked according to their PCA ranking values based on the HIS of seven parameters (WUE, Pn, RA, Chl content, RWC, and Fv/Fm, and TQ), with accessions 598892, 275660, 516605, 231565, and 598443 ranked as the top five accessions for heat tolerance and 311075, 538976, 278773, 610950, and 321681 ranked as the most heat-sensitive accessions (Table 3). Phenotypes of the top and least five heat tolerant ryegrass accessions were shown in Figure 3 that plants of the top-rated accessions had more green leaves or greener leaves while the most heat-sensitive accessions had more yellow or less green leaves.

To understand contributions of different traits to heat tolerance in perennial ryegrass, the relationships between PCA ranking based on HSI for overall heat tolerance and each physiological/phenotypic trait was determined using Pearson correlation analysis. As shown in Table 4, the PCA ranking was significantly correlated with all seven traits used in the evaluation $(p<0.05)$, among which ranking values of PCA and Chl content had the largest correlation coefficient $(r=0.864)$. And ranking values of TQ, RWC, and $\mathrm{Fv} / \mathrm{Fm}$ also showed high correlation coefficients with those of PCA $(r=0.840,0.833$, and 0.715 , respectively). Values of Pn and WUE had low correlation coefficients with those of PCA ( $\mathrm{r}=0.432$ and 0.309 , respectively), although their correlations were statistically significant as well $(p<0.05)$ (Table 4$)$.

\subsection{Transcript levels of chlorophyll-catabolic genes correlated to heat tolerance in perennial ryegrass}

Results of Pearson correlation analysis indicated that heat tolerance ranking based o PCA and Chl content had the largest correlation coefficient (Table 4), indicating leaf senescence characterized by Chl loss was mostly associated with overall heat tolerance in perennial ryegrass. To confirm the contribution of Chl catabolism to heat-tolerant accessions of perennial ryegrass, we further analyzed whether there was a correlation between transcription of four Chl catabolic genes (CCG s, including $L p N Y C 1, L p N O L, L p S G R$ , and $L p P P H$ ) and the PCA ranking values of heat tolerance of 98 ryegrass accessions. As shown in Figure 5, relative expression levels of $C C G$ s were significantly higher in heat-sensitive accessions than those in heat-tolerant accessions. The relationship between the relative expression levels of $C C G$ s and PCA ranking values were further analyzed using linear regression analysis and Pearson correlation coefficient analysis. As shown in Figure 6, relative expression levels of $L p N Y C 1, L p N O L, L p S G R$, and $L p P P H$ had strong positive correlations to PCA ranking values with $\mathrm{R}^{2}=0.943,0.878,0.814$, and 0.896 , respectively. 


\subsection{Classification of 98 accessions of perennial ryegrass based on SSR markers}

Genotypic diversity within the selected ryegrass accessions was estimated using 66 pairs of SSR molecular markers. The SSR analysis yielded 864 polymorphic bands in total, with an average of 13 and a range of 3 to 26 bands per pair of primers (Supplementary material 2). The resultant polymorphism information content (PIC) values varied from 0.16 to 0.93 , with an average of 0.70 ; while the gene diversity index (Di) values ranged 0.16 to 0.94 , with an average of 0.72 (Supplementary material 2), confirming that the selected accessions represented a diverse genetic pool of perennial ryegrass germplasm. An N-J dendrogram was constructed based on the SSR results, clustering the 98 ryegrass accessions into three groups: Cluster A, B, and $\mathrm{C}$ consisting of 14, 10, and 74 ryegrass accessions, respectively (Figure 4).

Values of PCA ranking of heat tolerance and physiological traits were averaged across ryegrass accessions in each phylogenetic cluster (Table 5), and the results showed that averaged PCA ranking values of accessions in cluster C (146.2) were significantly higher than those in clusters A and B (123.9 and 127.9, respectively), suggesting that accessions in clusters A and B were less heat tolerant than those in cluster C. Similar difference was also observed for $\mathrm{Chl}$ content, WUE, and RA for genotype ranking of heat tolerance in each phylogenetic cluster (Table 5).

\subsection{SSR markers associated with physiological traits in heat tolerance}

The associations between the 66 SSR markers and the seven physiological traits were further analyzed using a general linear model (GLM) in TASSEL. As shown in Figure 7 and Table 6, a total of 30 associations were identified between the SSR markers and the relative values of Chl content, Fv/Fm, Pn, WUE, and $\mathrm{RA}$ at $\mathrm{R}^{2}>0.05(p<0.01)$. We found that two markers M144 and rv0941, located on chromosome 4, were associated with Chl content. The markers Lp165, rv0941, DLF008, B3C10, B3B8, and B5E1, located on chromosomes 3, 4, 5, and 7, were associated with Fv/Fm. The marker rv0985-1, located on chromosome 6, was associated with Pn. Thirteen markers, including PRG, PR10, M4213, 25ca1, LPSSRH01A07, rv0985-1, rv0005, rv1133, LPSSRH02C11, rv0663, B3B7, LpHCA16B2, and PR37, located on chromosomes 1, 3, 4, 6, and 7, were associated with WUE. The markers M844, LPSSRH01A07, B3B7, B1A10, LpSSR100, LP194, rv0757, and LPSSRH02C11, located on chromosomes 1, 3, and 5, were associated with RA. No association was identified between SSR markers and TQ or RWC (Figure 7).

\section{DISCUSSION}

Plant heat tolerance is a complex trait that could be attributed by many phenotypic and physiological factors, including those parameters examined in this study, such as Fv/Fm, Pn, Chl content, WUE, and RWC, and root activity (Barnabas et al., 2010; Jiang \& Huang, 2001; Kahan et al., 2014; Larkindale et al., 2005; Shah et al., 2011; Zhang et al., 2019). Therefore, PCA integrating all those parameters was used to rank heat tolerance among 98 accessions of perennial ryegrass, with 598892, 275660, 516605, 231565, and 598443 ranked as the top five heat-tolerant accessions and 311075, 538976, 278773, 610950, and 321681 as the least heat-tolerant accessions. Similar strategy has been successfully adopted in stress tolerance evaluation in soybean (Glycine max . L.) and switchgrass (Panicum virgatum L.) (Bouslama \& Shapaugh, 1984; Liu et al., 2015; Wojcik-Jagła et al., 2013). Liu et al. (2015) have used PCA to analyze drought tolerance of 49 switchgrass accessions by integrating values of seven physiological traits and four morphological traits. Heat tolerance ranking was further associated with specific growth and physiological traits in this study.

Through Pearson correlation analysis, Chl content was found to be most closely linked to overall heat tolerance ranking based on PCA, followed by TQ, RWC, and Fv/Fm, while Pn and WUE had low correlation coefficients with those of PCA ranking for heat tolerance in 98 accessions of perennial ryegrass. These results suggested that $\mathrm{Chl}$ content or stay-green trait could be used as the major selection criterion for a large population of perennial ryegrass germplasm for elite heat tolerance, although TQ, RWC, and Fv/Fm were also found to be good indicators of heat tolerance.

Leaf senescence and Chl loss is the most remarkable phenotype of cool-season grass species after prolonged heat stress. Jespersenet al . (2016) showed that heat-induced Chl decline was mainly due to accelerated Chl 
degradation rather than attenuated Chl biosynthesis in Agrostis species, suggesting that Chl catabolism, rather than Chl biosynthesis, was the dominant mechanisms associated with heat tolerance in perennial grass species. Our previously work have found that the expression levels of three Chl catabolic genes, including $L p N Y C 1$, $L p N O L$, and $L p P P H$, were significant lower in a heat-tolerant genotype of perennial ryegrass than heat-sensitive genotype under heat stress. Moreover, the expression levels of these CCGs were negatively correlated to ROS level, while positively correlated to activities of ROS scavenging enzymes (Zhang et al., 2019). In the current study, we found that the transcript levels of four CCGs, including $L p N Y C 1$, $L p N O L$, $L p S G R$, and $L p P P H$, were strongly correlated to heat tolerance ranking, indicating that these CCGs could be used as marker genes to select for heat-tolerant plants with less Chl loss or staygreen traits in perennial ryegrass, and potentially applicable for other cool-season grass species as well. Thus, we considered that $\mathrm{Chl}$ content and Chl catabolic genes were reliable physiological trait and marker genes for evaluation of heat tolerance in perennial ryegrass accessions.

Understanding the genetic structure and phenotypic diversity is the basis of parental selection for trait improvement in breeding, such as for heat tolerance in this study. Barre et al. (2017) classified 213 perennial ryegrass accessions into three clusters according to their vegetative and reproductive investment traits (e.g. leaf growth parameters, tillering parameters, heading data and reproductive investment). SSRs derived from expressed sequence tags (ESTs) are most widely used marker system because they might be linked to known genes, lower cost for development, and having higher transferability among related species (Wang et al., 2018). In this study, the 98 accessions of perennial ryegrass were classified into three clusters according to clustering analysis using 66 pairs of SSR markers. The same sets of SSR markers have also been used to understand genetic diversity of various perennial ryegrass germplasm and identify alleles contributing to plant tolerance to salt, drought, submergence, and winter stress, as well as spring re-growth (Tang et al., 2013; Yu et al., 2011; Yu et al., 2013). Physiological traits positively correlated to heat tolerance, including Chl content, WUE, and RA had significantly greater levels in accessions in cluster C than those in cluster A and B based on SSR marker classification, suggesting that accessions in cluster C were more heat tolerant than those in cluster A and B, and variations in heat tolerance were related to their genetic structure in the population of perennial ryegrass examined in this study. Furthermore, the most heat-sensitive and -tolerant ryegrass accessions were identified in this study that could be used as base material for ryegrass breeding in the future.

SSR markers linked with important agronomic traits, e.g. crown rust resistance (Dumsday et a., 2003), submergence (Yu et al., 2011), and heading date (King et al., 2008) in perennial ryegrass have been identified. However, no genic SSR markers that are associated with heat tolerance in perennial ryegrass have been reported so far. In the present study, twenty-five SSRs linked to heat tolerance-related traits were detected in perennial ryegrass. Two markers LPSSRH01A07 and LPSSRH02C11, both located on chromosome 4, which were reported to be associated with relative growth rate under submergence stress (Yu et al., 2011), were correlated with WUE and RA in this study, suggesting a QTL in chromosome 4 could also affect heat tolerance. It is interesting to find that three markers M4213, B3B7, and PR37, located on chromosome 1 with $6 \mathrm{cM}$ apart, were linked to WUE. In addition, Lp165, DLF008, and B3C10 located on chromosome 7 with $12 \mathrm{cM}$ apart, were associated with Fv/Fm. Thus, it is most likely that a QTL for WUE and Fv/Fm located at chromosome 1 and 7, respectively. The results indicate that at least three candidate QTLs located in these chromosome positions play an important role in heat tolerance of perennial ryegrass.

\section{CONCLUSION}

In summary, heat tolerance varied widely among 98 accessions of perennial ryegrass examined in this study. The most and least heat-tolerant accessions were identified, and accessions in cluster $\mathrm{C}$ were relatively more heat tolerant than those in cluster A and B. Chl content and CCGs were reliable physiological trait and marker genes for heat stress tolerance assessment in perennial ryegrass. Furthermore, SSR markers associated with Chl content, Fv/Fm, Pn, WUE, and RA were also identified. The result highlighted the importance of Chl catabolism, either with a regulatory role in heat tolerance or as merely a passive indicator of heat-stress imposed damage, in heat tolerance of cool-season grasses. Such knowledge is of significance for heat-tolerance 
breeding of perennial ryegrass and for further studies on heat tolerance mechanisms in perennial ryegrass as well as in other cool-season grass species.

\section{FUNDING}

This study was supported by the Natural Science Foundation of Jiangsu Province (grant no. BK20180546) and the National Natural Science Foundation of China [grant Nos. 31802117 and 31772659].

\section{ACKNOWLEDGMENTS}

We thank United States Department of Agriculture's National Plant Germplasm System (USDA-GRIN) for kindly providing the ryegrass accessions.

\section{CONFLICT OF INTEREST}

There is no conflict of interest.

Table 1. Accession number (PI No.), origin, status, and genetic clusters of 98 perennial ryegrass accessions.

\begin{tabular}{|c|c|c|c|c|c|c|c|}
\hline Accession No. & Origin & Status $^{a}$ & Status $^{a}$ & Cluster & Accession No. & Origin & Status $^{\mathrm{a}}$ \\
\hline 287855 & Spain & Spain & $\mathrm{U}$ & $\mathrm{A}$ & 284823 & Australia & Australia \\
\hline 231606 & Portugal & Portugal & $\mathrm{U}$ & $\mathrm{A}$ & 231604 & Portugal & Portugal \\
\hline 610950 & Morocco & Morocco & $\mathrm{W}$ & $\mathrm{A}$ & 516605 & Yugoslavia & Yugoslavi \\
\hline 220178 & Afghanistan & Afghanistan & $\mathrm{W}$ & $\mathrm{A}$ & 371952 & Bulgaria & Bulgaria \\
\hline 265340 & Portugal & Portugal & $\mathrm{U}$ & $\mathrm{A}$ & 440474 & Former USSR & Former U \\
\hline 319018 & Spain & Spain & $\mathrm{U}$ & $\mathrm{A}$ & 265351 & Chile & Chile \\
\hline 410155 & South Africa & South Africa & $\mathrm{W}$ & $\mathrm{A}$ & 231576 & Algeria & Algeria \\
\hline 577251 & Morocco & Morocco & $\mathrm{W}$ & $\mathrm{A}$ & 418726 & France & France \\
\hline 231566 & Libya & Libya & $\mathrm{U}$ & $\mathrm{A}$ & 403868 & Canada & Canada \\
\hline 287849 & Spain & Spain & $\mathrm{U}$ & A & 231580 & Algeria & Algeria \\
\hline 239730 & Egypt & Egypt & $\mathrm{U}$ & $\mathrm{A}$ & 634205 & USA & USA \\
\hline 206376 & Cyprus & Cyprus & $\mathrm{U}$ & A & 198070 & Sweden & Sweden \\
\hline 268333 & Former USSR & Former USSR & $\mathrm{W}$ & $\mathrm{A}$ & 321681 & France & France \\
\hline 423136 & Spain & Spain & $\mathrm{W}$ & $\mathrm{A}$ & 266293 & Netherlands & Netherlar \\
\hline 182857 & Czech Republic & Czech Republic & $\mathrm{U}$ & $\mathrm{B}$ & 578763 & USA & USA \\
\hline 538976 & Russia & Russia & $\mathrm{C}$ & $\mathrm{B}$ & 321397 & Czech Republic & Czech Re \\
\hline 197270 & Finland & Finland & $\mathrm{CD}$ & $\mathrm{B}$ & 303020 & Sweden & Sweden \\
\hline 547390 & Iran & Iran & $\mathrm{W}$ & $\mathrm{B}$ & 231595 & Morocco & Morocco \\
\hline 204085 & Cyprus & Cyprus & $\mathrm{U}$ & $\mathrm{B}$ & 418721 & Belgium & Belgium \\
\hline 619474 & Romania & Romania & $\mathrm{CD}$ & B & 418722 & Luxembourg & Luxembo \\
\hline 306292 & Bolivia & Bolivia & $\mathrm{U}$ & $\mathrm{B}$ & 418741 & France & France \\
\hline 277848 & Cyprus & Cyprus & $\mathrm{U}$ & $\mathrm{B}$ & 619003 & Norway & Norway \\
\hline 231567 & Libya & Libya & $\mathrm{U}$ & $\mathrm{B}$ & 251224 & Yugoslavia & Yugoslavi \\
\hline 598911 & Tunisia & Tunisia & $\mathrm{W}$ & $\mathrm{B}$ & 628717 & Bulgaria & Bulgaria \\
\hline 598839 & Morocco & Morocco & $\mathrm{W}$ & $\mathrm{C}$ & 290368 & Hungary & Hungary \\
\hline 418712 & Yugoslavia & Yugoslavia & $\mathrm{U}$ & $\mathrm{C}$ & 376878 & New Zealand & New Zeal \\
\hline 277846 & Yugoslavia & Yugoslavia & $\mathrm{U}$ & $\mathrm{C}$ & 303037 & Sweden & Sweden \\
\hline 610802 & Norway & Norway & $\mathrm{W}$ & $\mathrm{C}$ & 420126 & Japan & Japan \\
\hline 231565 & Libya & Libya & $\mathrm{U}$ & $\mathrm{C}$ & 204880 & Turkey & Turkey \\
\hline 225825 & Denmark & Denmark & $\mathrm{U}$ & $\mathrm{C}$ & 265344 & Ireland & Ireland \\
\hline 204879 & Turkey & Turkey & $\mathrm{W}$ & $\mathrm{C}$ & 237187 & Netherlands & Netherlar \\
\hline 265342 & Ireland & Ireland & $\mathrm{C}$ & $\mathrm{C}$ & 577254 & Luxembourg & Luxembo \\
\hline 303026 & France & France & $\mathrm{C}$ & $\mathrm{C}$ & 274637 & Poland & Poland \\
\hline
\end{tabular}




\begin{tabular}{llllllll}
\hline Accession No. & Origin & Status $^{\mathbf{a}}$ & Status $^{\mathbf{a}}$ & Cluster & Accession No. & Origin & Status $^{\mathbf{a}}$ \\
\hline 275660 & Australia & Australia & $\mathrm{CD}$ & $\mathrm{C}$ & 298091 & Hungary & Hungary \\
418723 & Luxembourg & Luxembourg & $\mathrm{W}$ & $\mathrm{C}$ & 285101 & Australia & Australia \\
577273 & Turkey & Turkey & $\mathrm{W}$ & $\mathrm{C}$ & 505842 & Former USSR & Former U \\
577269 & Norway & Norway & $\mathrm{W}$ & $\mathrm{C}$ & 632542 & Hungary & Hungary \\
238938 & New Zealand & New Zealand & $\mathrm{U}$ & $\mathrm{C}$ & 610965 & Italy & Italy \\
267059 & Poland & Poland & $\mathrm{U}$ & $\mathrm{C}$ & 202451 & Argentina & Argentin \\
303027 & Denmark & Denmark & $\mathrm{C}$ & $\mathrm{C}$ & 231605 & France & France \\
317452 & Afghanistan & Afghanistan & $\mathrm{W}$ & $\mathrm{C}$ & 284826 & Australia & Australia \\
403907 & Canada & Canada & $\mathrm{C}$ & $\mathrm{C}$ & 502412 & Russia & Russia \\
278773 & Canada & Canada & $\mathrm{C}$ & $\mathrm{C}$ & 418714 & Italy & Italy \\
254898 & Iraq & Iraq & W & $\mathrm{C}$ & 598434 & Italy & Italy \\
267058 & Poland & Poland & $\mathrm{U}$ & $\mathrm{C}$ & 610926 & Tunisia & Tunisia \\
418736 & Switzerland & Switzerland & W & $\mathrm{C}$ & 420128 & Japan & Japan \\
598443 & Switzerland & Switzerland & W & $\mathrm{C}$ & 418707 & Romania & Romania \\
600878 & USA & USA & $\mathrm{C}$ & $\mathrm{C}$ & 598892 & Tunisia & Tunisia \\
303028 & Denmark & Denmark & $\mathrm{C}$ & $\mathrm{C}$ & 311075 & Romania & Romania \\
\hline
\end{tabular}

Status $^{\mathrm{a}}$ : Improvement status obtained from USDA germplasm bank. U: uncertain; W: wild; C: cultivar; CD: cultivated.

Table 2. Effects of treatments and genotypes, and the interaction effect between temperature and genotype on phenotypic traits. Abbreviations: Turf quality (TQ), photochemical efficiency (Fv/Fm), chlorophyll content (Chl, mg/g DW), photosynthesis rate $\left(\mathrm{Pn}, \mu \mathrm{mol} \mathrm{CO}_{2} / \mathrm{m}^{2} / \mathrm{s}\right)$, water use efficiency (WUE, $\mu \mathrm{mol} \mathrm{CO}_{2} / \mathrm{mmol}_{2} \mathrm{O}$ ), leaf relative water content (RWC, \%), root activity (RA, $\mathrm{mg} / \mathrm{g} \cdot \mathrm{h}$ ), leaf width $(\mathrm{LW}, \mathrm{cm})$, and maximum plant height $(\mathrm{PH}, \mathrm{cm})$.

\begin{tabular}{lllll}
\hline & Physiological traits & Physiological traits & Physiological traits & Physiological traits \\
\hline & $\mathbf{T Q}$ & $\mathbf{F v} / \mathbf{F m}$ & $\mathbf{C h l}$ & Pn \\
Treatment & $* * *$ & $* * *$ & $* * *$ & $* * *$ \\
Genotype & $* *$ & $*$ & $* *$ & $* *$ \\
Treatment X Genotype & $* * *$ & $* *$ & $* * *$ & $* * *$ \\
\hline
\end{tabular}

Table 3. Three major components (PC1, PC2, and PC3) and PCA ranking values of each ryegrass genotypes.

\begin{tabular}{llllllllllll}
\hline Accession No. & PC1 & PC2 & PC3 & PCA & Rank & Accession No. & PC1 & PC2 & PC3 & PCA & Rank \\
\hline 598892 & 393.1 & 27.7 & 18.3 & 221.5 & 1 & 265351 & 264.5 & -17.7 & 26.1 & 141.8 & 50 \\
275660 & 380.9 & 19.9 & 36.8 & 214.7 & 2 & 231606 & 270.5 & -36.4 & 38.7 & 141.7 & 51 \\
516605 & 362.2 & 21.3 & 33.9 & 204.6 & 3 & 287849 & 253.4 & -0.3 & 38.3 & 140.9 & 52 \\
231565 & 362.9 & -7.7 & 6.1 & 195.8 & 4 & 628717 & 262.1 & -25.2 & 44.5 & 140.3 & 53 \\
598443 & 334.6 & 41.0 & 45.5 & 195.2 & 5 & 265340 & 249.5 & 6.3 & 35.1 & 140.0 & 54 \\
303026 & 341.0 & 14.0 & 22.0 & 190.3 & 6 & 547390 & 250.0 & -0.3 & 32.3 & 138.5 & 55 \\
182857 & 339.7 & 11.2 & 21.2 & 188.9 & 7 & 418726 & 253.7 & -10.7 & 35.8 & 138.4 & 56 \\
610802 & 354.5 & -24.0 & 11.2 & 187.9 & 8 & 231566 & 258.5 & -26.8 & 33.7 & 137.1 & 57 \\
265342 & 338.0 & -13.1 & 30.1 & 183.1 & 9 & 619474 & 249.5 & -9.0 & 37.8 & 136.7 & 58 \\
277846 & 340.0 & -20.1 & 28.6 & 182.4 & 10 & 610965 & 252.9 & -15.3 & 29.6 & 136.3 & 59 \\
598839 & 297.3 & 74.4 & 26.3 & 181.1 & 11 & 420126 & 258.9 & -32.6 & 32.8 & 135.8 & 60 \\
251224 & 316.0 & 18.1 & 45.1 & 179.7 & 12 & 303020 & 243.0 & -2.4 & 38.1 & 134.7 & 61
\end{tabular}




\begin{tabular}{|c|c|c|c|c|c|c|c|c|c|c|c|}
\hline Accession No. & $\mathrm{PC} 1$ & $\mathrm{PC} 2$ & $\mathrm{PC} 3$ & $\mathrm{PCA}$ & Rank & Accession No. & $\mathrm{PC} 1$ & $\mathrm{PC} 2$ & PC3 & $\mathrm{PCA}$ & Rank \\
\hline 577254 & 308.8 & 28.8 & 46.4 & 178.4 & 13 & 284823 & 256.5 & -38.2 & 29.9 & 133.0 & 62 \\
\hline 231605 & 319.8 & -10.1 & 27.8 & 173.7 & 14 & 440474 & 213.3 & 39.4 & 41.8 & 128.7 & 63 \\
\hline 231604 & 310.2 & -0.9 & 26.3 & 170.5 & 15 & 376878 & 229.7 & 1.3 & 38.3 & 128.4 & 64 \\
\hline 418712 & 287.4 & 34.0 & 37.4 & 167.2 & 16 & 268333 & 228.8 & 2.5 & 41.3 & 128.4 & 65 \\
\hline 267059 & 282.7 & 35.6 & 47.0 & 165.9 & 17 & 317452 & 216.5 & 26.0 & 43.7 & 127.4 & 66 \\
\hline 303028 & 299.3 & -1.6 & 42.2 & 165.8 & 18 & 254898 & 232.3 & -6.3 & 29.2 & 127.2 & 67 \\
\hline 266293 & 299.4 & 0.5 & 34.8 & 165.7 & 19 & 231595 & 231.4 & -11.9 & 35.5 & 126.0 & 68 \\
\hline 418736 & 283.7 & 24.0 & 46.7 & 163.7 & 20 & 198070 & 232.2 & -13.3 & 32.1 & 125.8 & 69 \\
\hline 371952 & 309.1 & -27.4 & 23.7 & 163.5 & 21 & 502412 & 223.8 & -4.0 & 36.9 & 123.8 & 70 \\
\hline 418722 & 285.6 & 13.3 & 44.7 & 162.1 & 22 & 420128 & 227.8 & -15.1 & 33.2 & 123.1 & 71 \\
\hline 267058 & 299.3 & -20.7 & 34.5 & 160.7 & 23 & 418707 & 225.9 & -22.1 & 35.0 & 120.6 & 72 \\
\hline 225825 & 298.2 & -22.6 & 30.4 & 159.3 & 24 & 423136 & 232.0 & -39.1 & 28.0 & 119.3 & 73 \\
\hline 197270 & 275.9 & 17.1 & 44.7 & 157.7 & 25 & 577273 & 205.2 & 17.6 & 36.7 & 118.7 & 74 \\
\hline 600878 & 300.1 & -35.5 & 24.4 & 156.8 & 26 & 319018 & 226.4 & -30.7 & 31.2 & 118.5 & 75 \\
\hline 619003 & 274.2 & 18.5 & 41.3 & 156.8 & 27 & 277848 & 223.9 & -25.5 & 30.3 & 118.3 & 76 \\
\hline 238938 & 280.3 & 3.3 & 44.0 & 156.8 & 28 & 303027 & 198.7 & 31.1 & 32.5 & 118.0 & 77 \\
\hline 418723 & 280.4 & 5.3 & 35.0 & 156.5 & 29 & 410155 & 227.3 & -42.9 & 40.1 & 116.9 & 78 \\
\hline 505842 & 288.4 & -14.5 & 37.9 & 156.5 & 30 & 202451 & 208.2 & -1.7 & 34.7 & 115.7 & 79 \\
\hline 237187 & 286.6 & -11.2 & 36.1 & 156.2 & 31 & 265344 & 215.1 & -26.0 & 26.8 & 113.1 & 80 \\
\hline 274637 & 296.0 & -31.8 & 32.4 & 156.1 & 32 & 204879 & 211.2 & -21.6 & 34.0 & 112.6 & 81 \\
\hline 610926 & 298.0 & -37.5 & 30.7 & 155.7 & 33 & 577269 & 213.7 & -31.2 & 30.3 & 111.4 & 82 \\
\hline 285101 & 278.3 & -0.7 & 47.8 & 155.1 & 34 & 231576 & 212.9 & -28.9 & 28.3 & 111.3 & 83 \\
\hline 418741 & 272.9 & 13.7 & 30.5 & 154.0 & 35 & 632542 & 196.6 & 6.1 & 34.9 & 111.2 & 84 \\
\hline 287855 & 271.6 & 12.8 & 41.2 & 154.0 & 36 & 403868 & 202.6 & -12.9 & 30.5 & 109.6 & 85 \\
\hline 598911 & 260.7 & 34.2 & 51.5 & 154.0 & 37 & 231580 & 200.5 & -9.1 & 29.5 & 109.3 & 86 \\
\hline 303037 & 292.7 & -32.7 & 25.9 & 153.6 & 38 & 321397 & 204.9 & -16.6 & 20.7 & 109.2 & 87 \\
\hline 204880 & 277.1 & -6.3 & 41.9 & 152.6 & 39 & 239730 & 200.8 & -17.9 & 30.5 & 107.5 & 88 \\
\hline 284826 & 272.7 & 0.8 & 46.3 & 152.3 & 40 & 598434 & 204.3 & -27.5 & 33.3 & 107.4 & 89 \\
\hline 418721 & 269.0 & 8.4 & 43.3 & 151.8 & 41 & 418714 & 182.0 & 19.1 & 36.9 & 106.5 & 90 \\
\hline 578763 & 254.7 & 31.2 & 38.2 & 148.9 & 42 & 634205 & 185.5 & 13.0 & 26.8 & 106.1 & 91 \\
\hline 403907 & 270.9 & -13.5 & 34.6 & 146.9 & 43 & 206376 & 179.0 & 21.7 & 33.9 & 105.2 & 92 \\
\hline 298091 & 271.8 & -17.4 & 35.7 & 146.6 & 44 & 577251 & 188.7 & -23.6 & 32.0 & 99.7 & 93 \\
\hline 303032 & 276.5 & -27.6 & 30.5 & 146.4 & 45 & 311075 & 173.4 & 1.0 & 28.9 & 96.9 & 94 \\
\hline 231567 & 277.3 & -35.4 & 32.7 & 145.2 & 46 & 538976 & 159.4 & 19.0 & 20.7 & 92.8 & 95 \\
\hline 290368 & 277.4 & -40.1 & 33.5 & 144.2 & 47 & 278773 & 165.0 & -18.2 & 29.3 & 87.9 & 96 \\
\hline 220178 & 266.0 & -17.1 & 29.6 & 143.0 & 48 & 610950 & 153.5 & 4.6 & 36.4 & 87.6 & 97 \\
\hline 204085 & 256.0 & 0.0 & 40.4 & 142.5 & 49 & 321681 & 127.6 & -1.4 & 23.1 & 70.9 & 98 \\
\hline
\end{tabular}

Table 4. Pearson correlation coefficients analysis among the TQ, Fv/Fm, Chl content, Pn, WUE, RWC, RA, and PCA values.

\begin{tabular}{lllllllll}
\hline & PCA rank & TQ & Fv $/ F m$ & Chl & Pn & WUE & RWC & RA \\
\hline PCA & 1 & & & & & & & \\
TQ & $0.840^{* * *}$ & 1 & & & & & & \\
Fv $/$ Fm & $0.715^{* * *}$ & $0.755^{* * *}$ & 1 & & & & & \\
Chl & $0.864^{* * *}$ & $0.828^{* * *}$ & $0.693^{* * *}$ & 1 & & & & \\
Pn & $0.432^{* * *}$ & 0.136 & 0.097 & 0.115 & 1 & & & \\
WUE & $0.309^{* *}$ & -0.005 & -0.044 & 0.021 & $0.795^{* * *}$ & 1 & &
\end{tabular}




\begin{tabular}{lllllllll}
\hline & PCA rank & TQ & Fv/Fm & Chl & Pn & WUE & RWC & RA \\
\hline RWC & $0.833^{* * *}$ & $0.871^{* * *}$ & $0.727^{* * *}$ & $0.817^{* * *}$ & 0.107 & -0.028 & 1 & \\
RA & $0.595^{* * *}$ & $0.566^{* * *}$ & $0.466^{* * *}$ & $0.546^{* * *}$ & 0.066 & -0.061 & $0.518^{* * *}$ & 1 \\
\hline
\end{tabular}

** and $^{* * *}$ indicate significance at $P<0.01$ and $P<0.001$, respectively.

Table 5. Average values of TQ, Fv/Fm, Chl content, Pn, WUE, RWC, RA, and PCA of perennial ryegrass accessions classified in three phylogenetic clusters.

\begin{tabular}{lllllllll}
\hline Cluster & TQ & Fv/Fm & Chl & Pn & WUE & RWC & RA & PCA rank \\
\hline A & 4.41 & 0.65 & $6.11 \mathrm{~b}$ & 3.76 & $0.67 \mathrm{~b}$ & $57.91 \mathrm{~b}$ & $219.50 \mathrm{~b}$ & $123.9 \mathrm{~b}$ \\
B & 4.97 & 0.64 & $7.03 \mathrm{~b}$ & 3.83 & $0.65 \mathrm{~b}$ & $60.440 \mathrm{ab}$ & $223.91 \mathrm{~b}$ & $127.9 \mathrm{~b}$ \\
C & 5.05 & 0.65 & $7.72 \mathrm{a}$ & 3.77 & $0.77 \mathrm{a}$ & $63.44 \mathrm{a}$ & $234.71 \mathrm{a}$ & $146.2 \mathrm{a}$ \\
\hline
\end{tabular}

Table 6.Association of SSR markers with the heat stress index of TQ, Fv/Fm, Chl content, Pn, WUE, RWC, and RA.

\begin{tabular}{|c|c|c|c|c|c|}
\hline Trait & Locus & Chromosome No. & Position (cM) & $P$ value & $\mathbf{R}^{2}$ \\
\hline Fv/Fm & LP165 & 7 & 66 & $2.85 \mathrm{E}-06$ & 0.67 \\
\hline Fv/Fm & rv0941 & 4 & 20.3 & $6.57 \mathrm{E}-05$ & 0.47 \\
\hline Fv/Fm & DLF008 & 7 & 77 & $4.74 \mathrm{E}-04$ & 0.49 \\
\hline Fv/Fm & B3C10 & 7 & 80 & $3.68 \mathrm{E}-03$ & 0.29 \\
\hline Fv/Fm & B3B8 & 3 & 70 & $8.18 \mathrm{E}-03$ & 0.48 \\
\hline Fv/Fm & B5E1 & 5 & $\mathrm{NA}$ & $9.20 \mathrm{E}-03$ & 0.19 \\
\hline Chl & M144 & 4 & 56 & $5.21 \mathrm{E}-03$ & 0.52 \\
\hline Chl & rv0941 & 4 & 20.3 & $5.60 \mathrm{E}-03$ & 0.37 \\
\hline Pn & rv0985-1 & 6 & 51.7 & 8.92E-03 & 0.64 \\
\hline WUE & PRG & 4 & 119 & $3.98 \mathrm{E}-06$ & 0.53 \\
\hline WUE & PR10 & NA & NA & $4.50 \mathrm{E}-06$ & 0.47 \\
\hline WUE & M4213 & 1 & 46 & $1.78 \mathrm{E}-04$ & 0.44 \\
\hline WUE & $25 \mathrm{ca} 1$ & 3 & 91.1 & $2.25 \mathrm{E}-04$ & 0.56 \\
\hline WUE & LPSSRH01A07 & 3 & NA & $3.34 \mathrm{E}-04$ & 0.33 \\
\hline WUE & rv0985-1 & 6 & 51.7 & $5.99 \mathrm{E}-04$ & 0.70 \\
\hline WUE & rv0005 & 7 & 0 & $4.28 \mathrm{E}-03$ & 0.75 \\
\hline WUE & rv1133 & 3 & 27.8 & $4.52 \mathrm{E}-03$ & 0.17 \\
\hline WUE & LPSSRH02C11 & 3 & NA & $4.97 \mathrm{E}-03$ & 0.37 \\
\hline WUE & rv0663 & 7 & 6.7 & $6.88 \mathrm{E}-03$ & 0.31 \\
\hline WUE & B3B7 & 1 & 49 & 7.87E-03 & 0.29 \\
\hline WUE & LpHCA16B2 & 4 & 0 & 8.79E-03 & 0.48 \\
\hline WUE & PR37 & 1 & 52 & $9.62 \mathrm{E}-03$ & 0.48 \\
\hline RA & M844 & NA & NA & $3.01 \mathrm{E}-06$ & 0.60 \\
\hline RA & LPSSRH01A07 & 3 & NA & $1.05 \mathrm{E}-04$ & 0.35 \\
\hline RA & B3B7 & 1 & 49 & $7.47 \mathrm{E}-04$ & 0.35 \\
\hline RA & B1A10 & 3 & 74 & $9.35 \mathrm{E}-04$ & 0.63 \\
\hline RA & LpSSR100 & 3 & 62 & $2.60 \mathrm{E}-03$ & 0.21 \\
\hline RA & LP194 & NA & NA & $3.12 \mathrm{E}-03$ & 0.47 \\
\hline RA & rv0757 & 5 & 77.7 & 4.87E-03 & 0.72 \\
\hline RA & LPSSRH02C11 & 3 & NA & $7.88 \mathrm{E}-03$ & 0.36 \\
\hline
\end{tabular}




\section{FIGURE LEGENDS}

FIGURE 1. Heatmap and hierarchical clustering for physiological and morphological parameters under control and heat stress conditions in 98 ryegrass accessions after $24 \mathrm{~d}$ of treatment. Abbreviations: WUE, water use efficiency; Pn, photosynthesis rate; RA, root activity; Chl, chlorophyll content; RWC, leaf relative water content; Fv/Fm, photochemical efficiency; PH, maximum plant height; LW, leaf width.

FIGURE 2. Principal component analysis biplot of the heat stress index (HSI) of 98 ryegrass accessions. Arrows represent physiological and morphological traits with various lengths based on the impact of each trait on the separation of accessions. Accessions marked with green color in group $\mathrm{i}$ and red color in group ii are the ten most and least heat tolerant genotypes, respectively. Abbreviations: WUE, water use efficiency; Pn, photosynthesis rate; RA, root activity; Chl, chlorophyll content; RWC, leaf relative water content; Fv/Fm, photochemical efficiency; PH, maximum plant height; LW, leaf width.

FIGURE 3. Phenotypes of the five most and least heat tolerant ryegrass accessions. Pictures were taken after $24 \mathrm{~d}$ of treatment. Bar in each photo represents $6.5 \mathrm{~cm}$ in length.

FIGURE 4. Neighbour-joining tree of 98 perennial ryegrass accessions based on SSR markers.

FIGURE 5. Relative expression levels of four CCGs of the five most and least heat-tolerant ryegrass accessions. Relative expression levels of $L p N Y C 1$ (A), $L p N O L$ (B), $L p S G R$ (C), and $L p P P H$ (D). Represented data were means and standard error $(n=4)$.

FIGURE 6. Correlation between relative expression levels of four CCGs and PCA ranking values. Different spots in A-D indicate the gene relative expression levels and PCA ranking values of each accessions.

FIGURE 7. Manhattan plots of the general linear model (GLM) for association analysis between SSR markers and each physiological trait. The $-\log _{10}(P$-values $)$ from each SRR markers are plotted against seven heat tolerance-related traits, including TQ, Fv/Fm, Chl content, Pn, WUE, RWC, and RA.

\section{SUPPLEMENTARY DATA}

Supplementary table 1. Primers used for gene expression analysis.

Supplementary table 2. Eigenvectors and percentage of accumulated contribution ratios of each principal component.

Supplementary table 3. Principle component analysis of eight physiological traits across 98 perennial ryegrass accessions using heat stress index (HSI) after 24 days of treatment.

Supplementary materials 1 . The linkage group, physical distance, and primer sequences of 66 SSRs used in this study.

Supplementary materials 2. The major allele frequency, polymorphic bands, polymorphism information content, and gene diversity index of 66 pairs of SSR used for genetic diversity analysis in 98 ryegrass accessions.

\section{REFERENCES}

Altpeter, F., Xu, J., \& Ahmed, S. (2000). Generation of large numbers of independently transformed fertile perennial ryegrass (Lolium perenne L.) plants of forage- and turf-type cultivars. Molecular Breeding , 6 , 519-528.

Arnon, D. I. (1949). Copper enzymes in isolated chloroplasts, polyphenoloxidase in beta vulgaris. Plant Physiology, 24, 1. 
Barnabás, B., Jäger, K., \& Fehér, A., (2010). The effect of drought and heat stress on reproductive processes in cereals. Plant Cell \& Environment, 31, 11-38.

Barre, P., Ruttink, T., Muylle, H., Lootens, P. J., Sampoux, P., Rohde, A., Combes, D., \& Roldán-Ruiz, I., (2017). Natural diversity in vegetative and reproductive investments of perennial ryegrass is shaped by the climate at the place of origin. Grass and Forage Science, $73,13$.

Bouslama, M., \& Schapaugh, W. T. (1984). Stress tolerance in soybeans. I. Evaluation of three screening techniques for heat and drought tolerance. Crop Science, 24 , 933-937.

Bradbury, P.J. Zhang, Z. Kroon, D. E., Casstevens, R. M., Ramdoss, Y., \& Buckler, E. S. (2007). TASSEL: software for association mapping of complex traits in diverse samples. Bioinformatics , 23 , 2633-2635.

Burgess, P., \& Huang, B. (2014). Growth and physiological responses of creeping bentgrass (Agrostis stolonifera ) to elevated carbon dioxide concentrations. Horticulture Research , 1 , 28-30.

Cao, X., Mondal, S., Cheng, D., Wang, C., Liu, A., Song, J., Li, H., Zhao, Z., \& Liu, J. (2015). Evaluation of agronomic and physiological traits associated with high temperature stress tolerance in the winter wheat cultivars. Acta Physiologiae Plantarum, 37, 90.

Chastain, T. G., King, M. C., Garbacik, C. J., Young, W. C., \& Wysocki, D. J. (2015). Irrigation frequency and seasonal timing effects on perennial ryegrass (Lolium perenne L.) seed production.Field Crops Research , $180,126-134$.

Comas, L. H., Eissenstat, D. M., \& Lakso, A. N. (2000). Assessing root death and root system dynamics in a study of grape canopy pruning. New Phytologist , 147 , 171-178.

Dumsday, J. L., Smith, K. F., Forster, J. W., \& Jones, E. S. (2003). SSR-based genetic linkage analysis of resistance to crown rust (Puccinia coronata f. sp. lolii) in perennial ryegrass (Lolium perenne). Plant Pathology , 52, 628-637.

Flexas, J., Ribas-Carbó, M., Bota, J., Galmés, J., Henkle, M., Martínez-Cañellas, S., \& Medrano, H. (2006). Decreased Rubisco activity during water stress is not induced by decreased relative water content but related to conditions of low stomatal conductance and chloroplast $\mathrm{CO}_{2}$ concentration. New Phytologist , 172 , 73-82.

Hoagland, D. R., \& Arnon, D. I. (1950). The water-culture method for growing plants without soil. Circular California Agricultural Experimental Station, 347, 357-359.

Wang, H., Lei, Y., Yan, L., Wan, L., Cai, Y., Yang, Z., Lu, J., Zhang, X., Xu, C., \& Liao, B. (2018). Development and validation of simple sequence repeat markers from Arachis hypogaea transcript sequences. The Crop Journal , 2 , 7 .

Huang, G., Tong, W., Gui, Z., Wei, L., Zeng, Y., Zeng, Z., Yin, H., Liu, G., Zheng, J., Yao, Y., \& Li, Y. (2017). Principal component analysis for physicochemical characteristics of different fruit mulberry cultivars. Journal of Central South University of Forestry 83 Technology, 37, 19-23.

Huang, L., Yan, H., Jiang, X., Yin, G., Zhang, X., Qi, X., Zhang, Y., Yan, Y., Ma, X., \& Peng, Y. (2014). Identification of candidate reference genes in perennial ryegrass for quantitative RT-PCR under various abiotic stress conditions. PLoS One, 9 , e93724.

Jespersen, D., Merewitz, E., Xu, Y., Honig, J., Bonos, S., Meyer, W., \& Huang, B. (2016). Quantitative trait loci associated with physiological traits for heat tolerance in creeping bentgrass. Crop Science, 56 , 1314-1329.

Jespersen, D., Belanger, F. C., \& Huang, B. (2017). Candidate genes and molecular markers associated with heat tolerance in colonial bentgrass.Plos One, 12 , e0171183.

Jespersen, D., Zhang, J., \& Huang B. (2016). Chlorophyll loss associated with heat-induced senescence in bentgrass. Plant Science, 249, 1-12. 
Jiang, Y., \& Huang, B. (2001). Drought and heat stress injury to two cool-season turfgrasses in relation to antioxidant metabolism and lipid peroxidation. Crop Science , 41, 436-442.

Kahan, A.R., Cheng, Z., Ghazanfar, B., Kahan, M. A., \& Zhu, Y. (2014). Acetyl salicylic acid and 2, 4epibrassinolide enhance root activity and improve root morphological features in tomato plants under heat stress.Acta Agriculturae Scandinavica, Section B-Soil \& Plant Science ,64, 304-311.

King, J., Thorogood, D., Edwards, K. J., Armsterad, L., Roberts, K., Skot, Z., Hanley, \& King, I. P. (2008). Development of a genomic microsatellite library in perennial ryegrass (Lolium perenne) and its use in trait mapping. Annals of Botany , $101,845-853$.

Krans, J. V., Philley, H. W., Goatley, J. M. Maddox, V. L. (2000). Registration of twelve creeping bentgrass germplasms selected in Mississippi. Crop Science, 40, 582.

Larkindale, J., Hall, J. D., Knight, M. R., \& Vierlin, E. (2005). Heat stress phenotypes of Arabidopsis mutants implicate multiple signaling pathways in the acquisition of thermotolerance. Plant Physiology, 138 , 882-897.

Li, C., Song, L., Zhu, Y., Zhai, Y., \& Wang, Q. (2017). Genetic diversity assessment of upland cotton variety resources in China based on phenotype traits and molecular markers. Crop Science, 57, 290-301.

Liu, Y., Zhang, X., Tran, H., Shan, L., Kim, J., Childs, K., Ervin, E. H, Frazier, T, \& Zhao, B. (2015). Assessment of drought tolerance of 49 switchgrass (Panicum virgatum ) genotypes using physiological and morphological parameters. Biotechnology for Biofuels , 8 , 152.

Minner, D. D., Dernoeden, P. H., Wehner, D. J., \& McIntosh, M. S. (1983). Heat tolerance screening of field-grown cultivars of kentucky bluegrass and perennial ryegrass. Agronomy journal , 75 , 772-775.

Mondal, S., Singh, R., Huerta-Espino, J., Kehel, Z., \& Autrique, E. (2015). Characterization of heat- and drought-stress tolerance in high-yielding spring wheat. Crop Science , 55, 1552.

Nei, M. (19730. Analysis of gene diversity in subdivided populations.PNAS , 70 , 3321-3323.

Ober, E. S., Bloa, M. L. Clark, C. J. A., Royal, A., Jaggard, K. W., \& Pidgeon, J.D. (2005). Evaluation of physiological traits as indirect selection criteria for drought tolerance in sugar beet. Field Crops Research, $91,231-249$.

Oxborough, K., \& Baker, N. R., (1997). Resolving chlorophyll a fluorescence images of photosynthetic efficiency into photochemical and non-photochemical components-calculation of $\mathrm{qP}$ and Fv-/Fm-; without measuring Fo. Photosynthesis research, 54 , 135-142.

Annicchiaric, P., \& Pecetti, L. (1998). Yield vs. morphophysiological trait-based criteria for selection of durum wheat in a semi-arid Mediterranean region (northern Syria). Field Crops Research ,59 , 163-173.

Munns, R., Husain, S., Rivelli, A. R. James, R. A., Condon, A. G., Lindsay, M. P., Lagudah, E. S., Schachtman, D. P. \& Hare, R. A. (2002). Avenues for increasing salt tolerance of crops, and the role of physiologically based selection traits. Plant $\mathcal{E}$ Soil ,247, 93-105.

Shah, F., Huang, J., Cui, K., Nie, T., Shah, T., Chen, C., \& Wang, K. (2011). Impact of high-temperature stress on rice plant and its traits related to tolerance. Journal of Agricultural Science, 149 , 545-556.

Steponkus, P. L., \& Lanphear, F. O. (1967). Refinement of the triphenyl tetrazolium chloride method of determining cold injury. Plant Physiology , 42 , 1423-1426.

Tang, J., Yu, X., Luo, N., Xiao, F., Camberato, J. J., \& Jiang, Y. (2013). Natural variation of salinity response, population structure and candidate genes associated with salinity tolerance in perennial ryegrass accessions. Plant Cell E Environment, 36 , 2021-2033.

Turgeon, A. J. (1991). Turfgrass Management. Prentice-Hall Inc. 
Varshney, R. K. Baum, M. Guo, P., Grando, S., Ceccarelli, S., \& Graner, A. (2010). Features of SNP and SSR diversity in a set of ICARDA barley germplasm collection. Molecular Breeding , 26 , 229-242.

Wójcik-Jagła, M., Rapacz, M., Tyrka, M., Kościelniak, J., Crissy, K., \& Żmuda, K. (2013). Comparative QTL analysis of early short-time drought tolerance in Polish fodder and malting spring barleys. Theoretical and Applied Genetics , 126, 3021-3034.

Xu, Y., Wang, J., Bonos, S. A., Meyer W. A., \& Huang, B. (2018). Candidate genes and molecular markers correlated to physiological traits for heat tolerance in fine fescue cultivars. International Journal of Molecular Sciences, 19 .

Yu, X., Bai, G., Liu, S., Luo, N., Wang, Y., Richmond, D. S., Pijut, P. M, Jackson, S. A, Yu, J., \& Jiang, Y. (2013). Association of candidate genes with drought tolerance traits in diverse perennial ryegrass accessions. Journal of Experimental Botany , 64, 1537-1551.

Yu, X., Pijut, P. M., Byrne, S., Asp, T., Bai, G., \& Jiang, Y. (2015). Candidate gene association mapping for winter survival and spring regrowth in perennial ryegrass. Plant Science, 235, 37-45.

Yu, X., Bai, G., Luo, N., Chen, Z., Liu, S., \& Liu, J., Warnke, S. E., \& Jiang, Y. (2011). Association of simple sequence repeat (SSR) markers with submergence tolerance in diverse populations of perennial ryegrass.Plant Science , 180, 391-398.

Zhang, J., Shi, Y., Zhang, X., Du, H., Xu, B., \& Huang, B. (2017). Melatonin suppression of heat-induced leaf senescence involves changes in abscisic acid and cytokinin biosynthesis and signaling pathways in perennial ryegrass (Lolium perenne L.). Environmental and Experimental Botany , 138 , 36-45.

Zhang, Z., Zeng, W., Cai, Z., Lai, Z., Su, Y., Xing, G., Wang, W., Sun, Z., \& Gai, J. (2019). Differentiation and evolution among geographic and seasonal eco-populations of soybean germplasm in Southern China.Crop E Pasture Science, 70 , 121-132.

Zhang, J., Xing, J., Lu, Q., Yu, G., Xu, B., \& Huang, B. (2019). Transcriptional regulation of chlorophyllcatabolic genes associated with exogenous chemical effects and genotypic variations in heat-induced leaf senescence for perennial ryegrass. Environmental and Experimental Botany , 167,103858.

Zhu, X., Chang, G., He, D., Zhao, H., \& Ma, C. (2014). Evaluation of new onion varieties using cluster analysis and principal component analysis methods. Gansu Agricultural Science, 10, 25-28. 


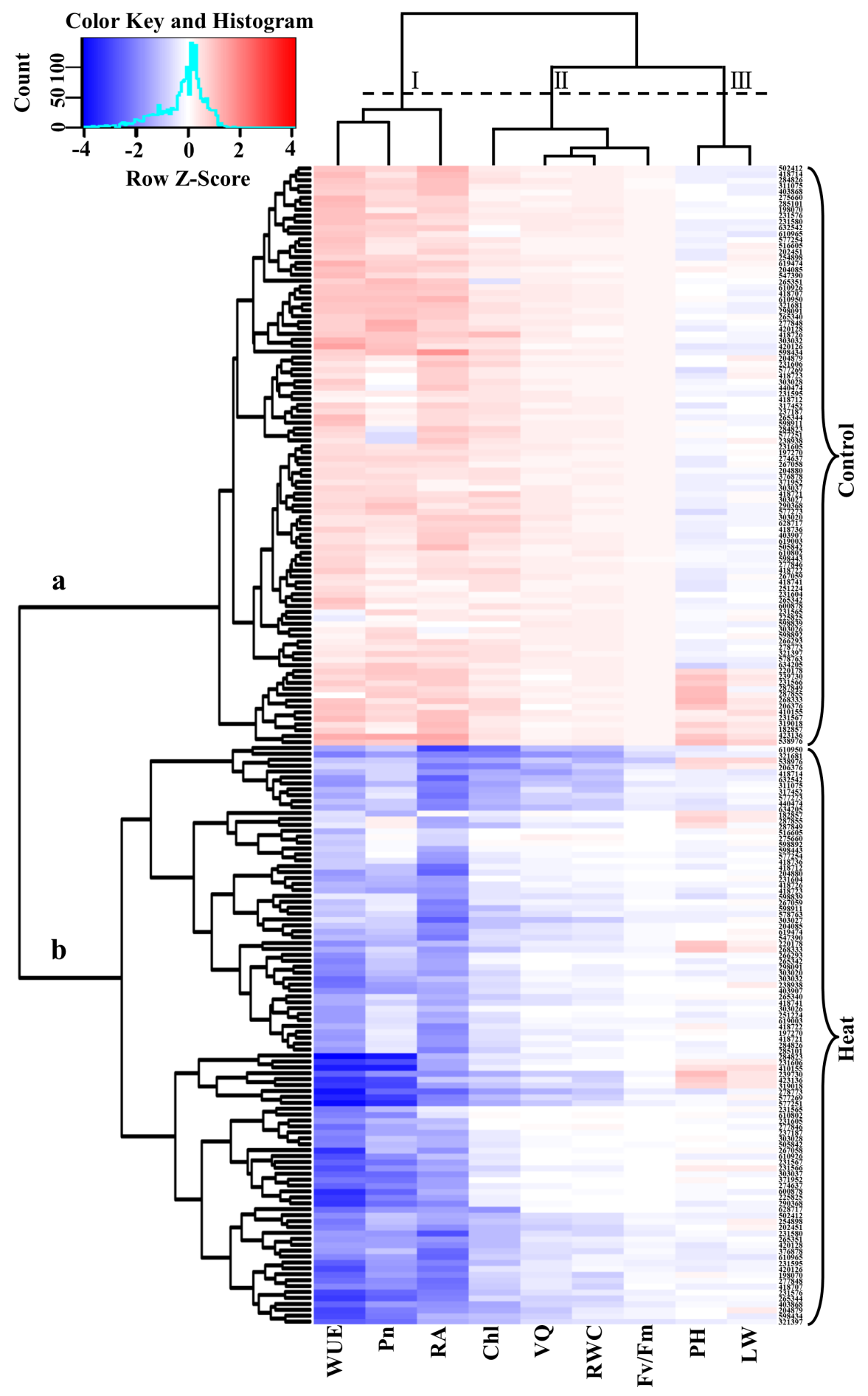



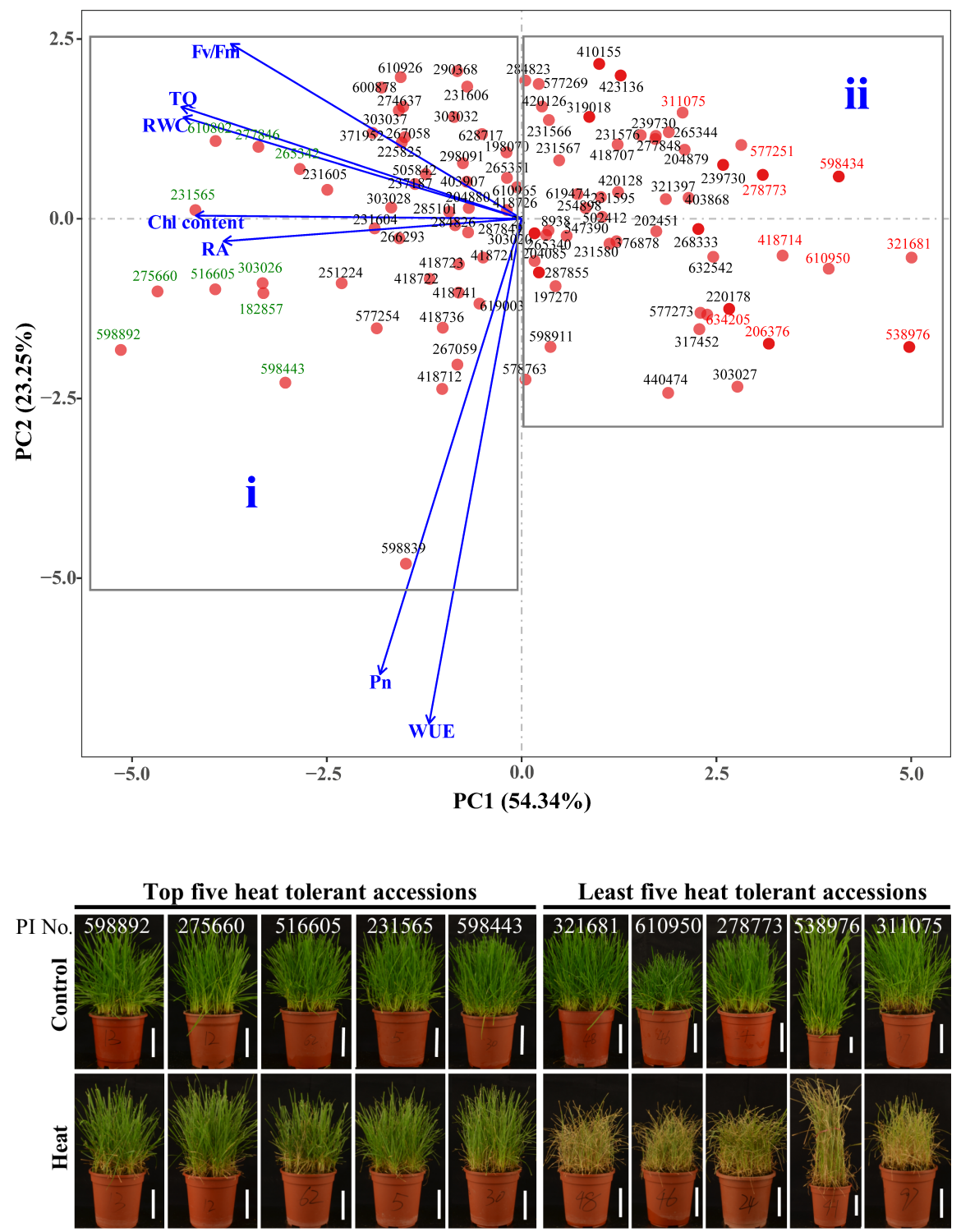

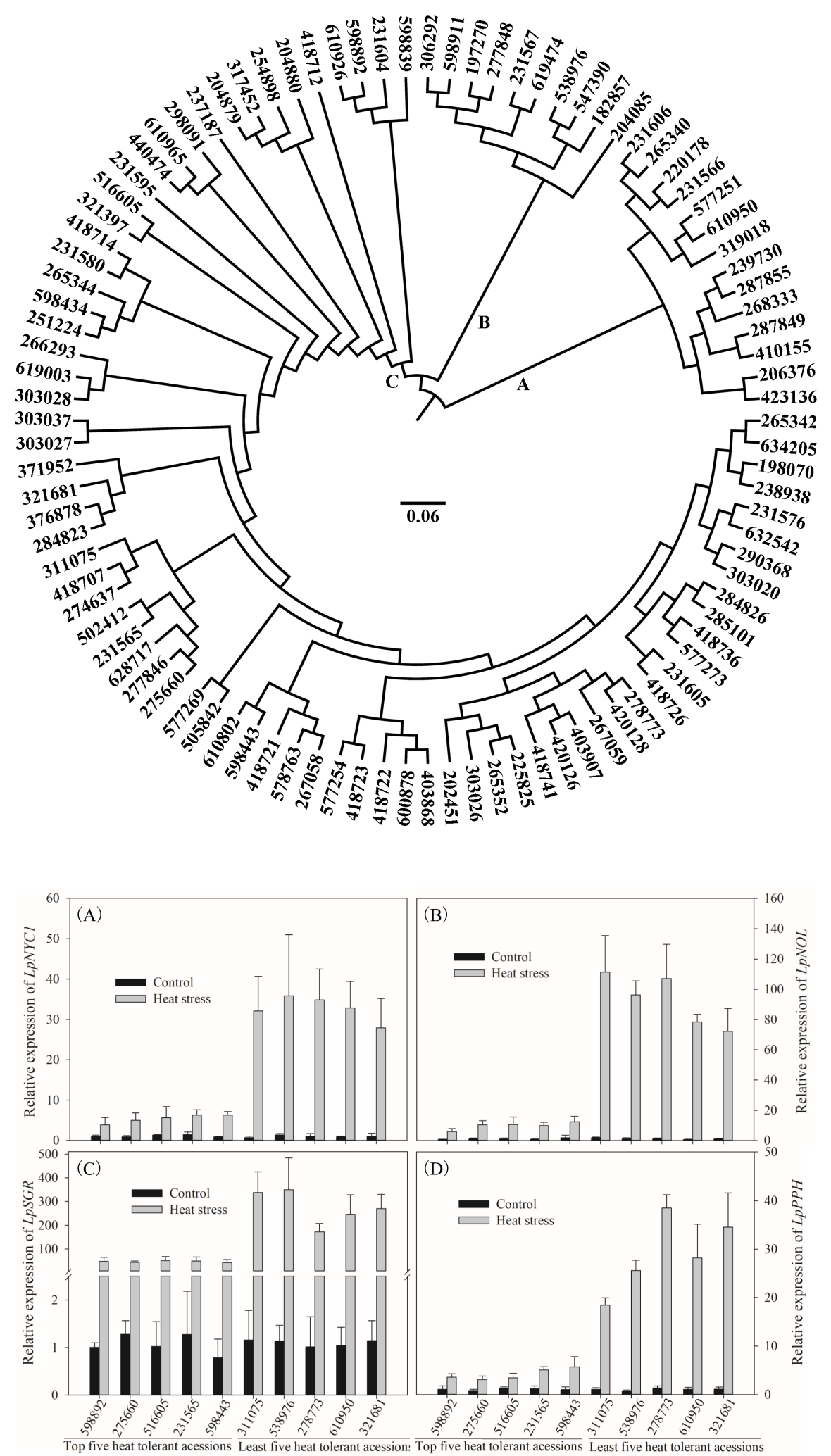

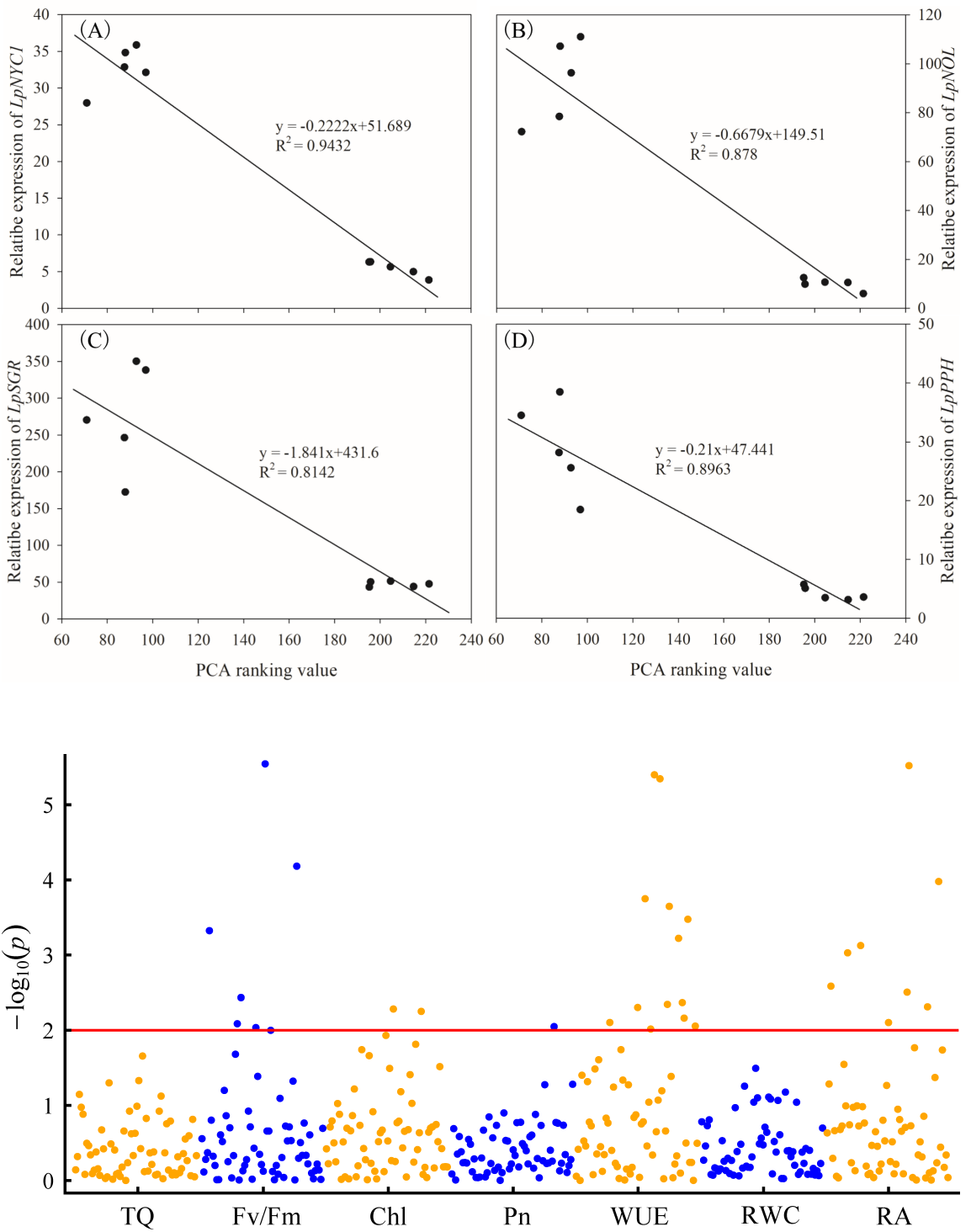